\title{
COVID-19 and E-Learning: the Challenges of Students in Tertiary Institutions
}

\author{
Emmanuel Aboagye $^{1^{*}}$, Joseph Anthony Yawson $^{2}$, Kofi Nyantakyi Appiah $^{3}$ \\ ${ }^{1}$ Physical Education Department Akrokerri College of Education, Ghana, Akrokerri, Ghana \\ ${ }^{2}$ Akrokerri College of Education, Akrokerri, Ghana \\ ${ }^{3}$ Wesley College of Education, Ghana \\ E-mail: aboagyeemmanuel13@yahoo.com, tonyawsongh@gmail.com, nyantakyi.appiah@ymail.com
}

Received: 13 May 2020; Revised: 28 June 2020; Accepted: 30 June 2020

\begin{abstract}
Problems associated with the transition from conventional learning (face to face) to online learning (e-learning) in the educational system are well documented. The present study explores the challenges students in tertiary institutions have reported facing in online learning in the era of coronavirus pandemic. Using a sample $(\mathrm{n}=141)$, an initial principal component factor analysis was conducted to group the constructs. Eight groups that emerged were social issues, lecturer issues, accessibility issues, learner motivation, academic issues, generic issues, learner intentions, and demographics. Cronbach's alpha was used to determine the reliability of the scales resulting in the deletion of learner motivation. Comparing the means of the factors revealed that the most important challenge for students to study online was accessibility issues. This was followed by social issues, lecturer issues, academic issues, and generic issues. The mean for the individual items in learners' intention to study online showed that students were not ready to study online. A Multiple Regression Analysis was further conducted to determine which factors pose the most important challenges to the student's decision to study online. Social issues and lecturer issues were significant. In the final model, only lecturer issues were significant. A blended approach-where conventional teaching is combined with online teaching should have ushered the learners to complete online learning.
\end{abstract}

Keywords: e-learning, COVID-19, convectional education, challenges, blended learning

\section{Introduction}

\subsection{Background of the study}

According to the World Health Organisation (WHO, 2020), coronavirus disease (COVID-19) is an infectious disease caused by a newly discovered coronavirus. The WHO further asserted that people infected with the COVID-19 virus experience mild to moderate respiratory illness and recover without requiring special treatment. However, older people and those with underlying health conditions such as diabetes, cardiovascular disease, chronic respiratory disease, and cancer are more likely to develop severe sickness and deaths. Despite the number of public education on how to prevent and slow the transmission of the disease, the disease has spread globally to 210 countries and territories around the world with a total of 2,013,918 confirmed cases of the COVID-19 that originated from Wuhan, China, and a death

Copyright (C2020 Emmanuel Aboagye, et al.

DOI: https://doi.org/10.37256/ser.212021422

This is an open-access article distributed under a CC BY license

(Creative Commons Attribution 4.0 International License)

https://creativecommons.org/licenses/by/4.0/ 
toll of 127,587 deaths (Worldometer, 2020).

The disease was discovered through whole-genome sequencing, polymerase chain reaction and bronchoalveolar fluid from infected persons (Zhou et al., 2020; Zhu et al., 2020). The mode of spread from humans to humans created the need for social distancing and avoidance of crowded places. Considering this, most governments have shut down schools and institutions where crowds cannot be avoided until further notice. The unexpected closure of educational institutions prompted the authorities to suggest emergency remote teaching to ensure that students are not left idle in this pandemic era. Therefore, the conventional methods (traditional face to face teaching) have been replaced by online (e-learning) for the time being. Comparing the developed world to the developing countries, it was found that developing countries are facing challenges such as poor internet connectivity, inadequate knowledge on the use of ICT and weakness of content development (Aung \& Khaing, 2015). For instance, delivering content like video and other applications is still new to many educators even at the tertiary level in developing countries. This new trend demands better technology and educators changing their workplace culture. An important factor to consider before implementing e-learning is whether the learners are ready and will be successful in an online environment (Guglielmino \& Guglielmino, 2003; Watkins et al., 2004). Although learners may demonstrate success in conventional education and classroom, that alone is not enough to guarantee success in an online learning situation (Watkins et al., 2004).

\subsection{Literature review}

In the literature, several studies have addressed the challenges associated with the introduction of e-learning. There has been evidence that the introduction of electronic learning initiatives has failed because institutions and their constituents were not prepared for the experience (Aydin \& Tasci, 2005; Borotis \& Poulymenakou, 2004). Besides, people are attached to already existing pedagogies and practices making it difficult for them to adjust to innovations and upgrade existing ones (Watkins et al., 2004). Carr (2000) was of the view that student perception about on-line learning has been negative due to past experiences resulting in high dropouts and low motivation of learner (Maltby \& Whittle, 2000). Other factors were found to be low student satisfaction associated with online learning experience (Kenny, 2003). Nonetheless, research suggests that students and instructors are satisfied with online learning just like traditional learning (Ali \& Ahmad, 2011).

The increase in the number of students participating in distance education supports online learning as a substitute for traditional classroom teaching. Martin and Boliger (Martin \& Bolliger, 2018) found that icebreaker/introduction and working with online communication tools were the most important engagement among learners while sending reminders and providing rubrics for assignments constituted the most important benefit in learner-instructor interactions. Similarly, Zaheer, Gondal, and Qadri (2015) identified that many students were satisfied with the education received online which further revealed that e-learning can support higher education in countries where higher education institutions are limited. Factors found to contribute to student satisfaction were embodied in the tutorials, student contribution, the type of instructor, mode of assessment, the content, learning environment, and the resources used (Zaheer et al., 2015). The issue at hand is not associated with limitation in higher educational institutions but a situation demanding for an emergency remote teaching because social gatherings including educational institutions are seen as a threat to promote COVID-19 pandemic and has been locked down. Therefore, this study focused primarily on the challenges that students are expected to face in online learning.

On the contrary, students perceived barriers to online learning have been documented. Muilenburg and Berge (2005) asserted that administrative issues, academic skills, social interactions, technical skills, learner motivation, time and support for studies, cost, and access to the internet and technical problems were some of the challenges associated with online learning. Regarding this, the present study aimed to examine the challenges of students in Ghana on how to cope with e-learning in this COVID-19 era and examined whether students were ready to study online. The following research questions guided the study-what are the most important challenges facing students at tertiary institutions in Ghana in an online learning situation? Are students at tertiary institutions in Ghana prepared for an online learning experience? Can social issues, lecturer issues, accessibility issues, learner motivations, academic issues, and generic issues predict the dependent variable-students' intention to study online? 


\section{Methodology}

The current study was conducted using a quantitative method. Most of the questions were developed from Muilenberg and Berg (2005) questionnaire on similar studies but were adjusted to meet the Ghanaian student environment. The questionnaire reported a 0.94 reliability of Cronbach Alpha. The Kaiser-Meyer-Olkin-Measure of sampling adequacy was $0.89-0.97$ for the individual variables. The questionnaire was made up of 30 items in all. The first section was made up of three items that measured the demographic information of the participants. The remaining sections measured five main challenges of lecturer issues, social issues, academic skills, cost, and access to internet and learner motivation. The last section was to examine the intention of the learners to study online. All the items apart from the demographic information were measured with a five-point Likert-scale ranging from (1) strongly disagree to (5) strongly agree.

\subsection{Procedure and participants}

"Google forms" was applied to develop the questionnaire and the link was posted on WhatsApp pages of the students through contact with their lecturers. Vasantha Raju and Harinarayana (2016) propounded that the google forms can reach a large population of participants at different locations and at the same time save cost. Considering the different locations of the students employed in the present study, the google form was considered appropriate. A Purposive sampling technique was employed to select the participants as the researchers were interested in getting detailed information about the research questions (Buchanan, 2012). Again, purposive sampling requires personal judgement to select cases that enable to answer the research question or achieve the research objectives (Dudovskiy, 2018). Students in tertiary institutions in Ghana were asked to share their experiences in an online learning situation as they have just transitioned from conventional to online learning. Most of the participants live in urban areas with an average age of 18 years. The participants were asked to voluntarily participate in the study and an informed consent was sought before the study began. Participants were asked to click next if they adhered to the ethical issues explained in the introductory part of the questionnaire. The intent was to get about 500 responses, but 141 responses were returned usable. After looking through the responses carefully, 6 were deleted for further analysis as they contained too many items that were not answered, and also they had the same rating for every item, thus, indicating that the participants have not selected their answers with the necessary attention.

\subsection{Data analysis}

The statistical analysis of the data was conducted using the Statistical Package for the Social Sciences (SPSS version 2018). A principal component factor analysis (PCFA) with a varimax rotation was used to identify the factors in the study. Means were used to identify the factors that were more perceived as challenges students will encounter in an online learning situation. The reliability of the scales was determined by the use of Cronbach Alpha. The mean, the standard deviation, and Cronbach Alpha of all the individual items were also examined. Besides, a multiple regression analysis was conducted to determine if social issues, lecturer issues, accessibility, learner motivations, academic issues, and generic issues can predict the dependent variable-intention to attend lectures. Percentages and frequency counts were used to analyse the demographic information of the participants.

\section{Results}

Kaiser-Meyer-Olkin Measure of Sampling Adequacy was 0.839 above the accepted value of 0.600 . Bartlett's Test of Sphericity was $\left(X^{2}(435)=1930.390, p<0.001\right.$. The communalities were all above 0.500 confirming that the items shared a common variance with the other items. Considering this, factor analysis was considered ideal for the 30 items.

The PCFA for the 30 items used in the survey were put into eight factors namely: social issues $32.105 \%$, lecturer issues $7.333 \%$, accessibility $6.176 \%$, learner motivation $5.020 \%$, academic issues $4.660 \%$, generic issues $4.399 \%$, learner intentions $4.035 \%$ and demographics $3.713 \%$ which in total accounted for $67.4 \%$ of the variance. One of the items was deleted because it was found to be negative under the component and in a different direction. Due to the 
low Cronbach's Alpha, learner motivation was rejected for further analysis. Afterward, the Cronbach Alpha, the mean and standard deviation of all the items were identified (see Table 1). With an alpha of 0.65-0.80 proven acceptable for research involving human participants (Green et al., 1977; Vaske, 2008), the scales were considered reliable (Table 1). The respondents were mostly males (59.3\%), with 51.9\% at level 200 , while $72.6 \%$ have used online learning.

Table 1. Factors, items, descriptive statistics (mean-M and standard deviation-SD and Cronbach's alpha- $\alpha$ )

\begin{tabular}{|c|c|c|c|c|}
\hline Factors & Items & M & SD & $\alpha$ \\
\hline \multirow[t]{6}{*}{ Social Issues } & & & & 0.89 \\
\hline & online learning is too personal & 4.29 & 1.06 & \\
\hline & Lack of communication among learners & 4.12 & 1.15 & \\
\hline & Lack of group discussions during assignments & 4.31 & 1.15 & \\
\hline & Online learning is too indirect & 4.36 & 1.05 & \\
\hline & Makes learners isolated & 4.34 & 1.02 & \\
\hline \multirow[t]{6}{*}{ Lecturer Issues } & & & & 0.86 \\
\hline & Lower quality of materials online & 3.76 & 1.28 & \\
\hline & Lack of clear learning expectation from lecturers & 4.04 & 1.24 & \\
\hline & Inadequate instructors to assist in lesson delivery & 4.03 & 1.23 & \\
\hline & Course materials will be delayed online & 3.59 & 1.44 & \\
\hline & Lecturers or instructors are not trained to teach & 3.84 & 1.35 & \\
\hline \multirow[t]{6}{*}{ Accessibility Issues } & & & & 0.79 \\
\hline & The required technology is unavailable & 4.41 & 1.06 & \\
\hline & Some phones and laptops are not compatible & 4.46 & 0.95 & \\
\hline & Issues with correct browsers for learning & 4.5 & 0.86 & \\
\hline & Lack of adequate internet access & 4.49 & 1.04 & \\
\hline & Cost of internet bundle is too high & 4.8 & 0.56 & \\
\hline \multirow[t]{3}{*}{ Academic Issues } & & & & 0.69 \\
\hline & Lack of effective communication skills & 4.41 & 1.18 & \\
\hline & Lack of reading skills & 3.34 & 1.40 & \\
\hline \multirow[t]{3}{*}{ Generic skills } & & & & 0.73 \\
\hline & Lack of good writing skills & 3.79 & 1.31 & \\
\hline & Lack of vocabulary acquisition & 3.73 & 1.29 & \\
\hline \multirow[t]{6}{*}{ Learner Intentions } & & & & 0.79 \\
\hline & I prefer online learning should be halted & 4.00 & 1.45 & \\
\hline & I prefer the semester to be postponed & 4.30 & 1.18 & \\
\hline & The online learning environment is not motivating & 4.33 & 1.08 & \\
\hline & Online learning cannot achieve learner objectives & 4.22 & 1.23 & \\
\hline & I lack personal motivation for online learning & 4.10 & 1.14 & \\
\hline
\end{tabular}

To determine the most important challenge learners face in an online learning situation, the means of the variables were compared see (Table 2). 
Table 2. The most important challenges learners face in an online learning situation

\begin{tabular}{ccc}
\hline & Mean & Std. Deviation \\
\hline Accessibility_issues & 4.53 & 0.67 \\
Social_Issues & 4.29 & 0.91 \\
Lecturer_issues & 3.85 & 1.05 \\
Academic_issues & 3.78 & 1.10 \\
Generic_issues & 3.75 & 1.16 \\
\hline
\end{tabular}

From Table 2 it is obvious that accessibility issues with a mean of 4.53 are an important challenge facing students in an online learning situation followed by social issues, lecturer issues academic issues and generic issues. Despite the participants selecting accessibility issues as the most important challenge, all the other challenges reported mean of more than 3 out of possible 5 .

To determine student's readiness to participate in online learning during the COVID-19 pandemic, the mean and standard deviations of five items measured were used (Table 3).

Table 3. Students readiness to study online

\begin{tabular}{|c|c|c|}
\hline Item & Mean & Standard Deviation \\
\hline $\begin{array}{l}\text { I prefer online learning to be halted to concentrate on } \\
\text { COVID-19 pandemic }\end{array}$ & 4.00 & 1.45 \\
\hline $\begin{array}{l}\text { Online learning cannot help to achieve course } \\
\text { objective }\end{array}$ & 4.22 & 1.23 \\
\hline $\begin{array}{l}\text { I prefer the semester to be postponed until further } \\
\text { notice }\end{array}$ & 4.30 & 1.18 \\
\hline I lack personal motivation for learning online & 4.10 & 1.14 \\
\hline The online learning environment is not motivating & 4.33 & 1.08 \\
\hline
\end{tabular}

The results from the table show that students were not prepared for online learning. All the items reported a mean of more than 4.00 out of possible 5.00 .

To identify the factors that are more likely to challenge learner's intention to study online, a hierarchical multiple regression analysis was conducted with social issues, lecturer issues, accessibility, academic issues, and generic issues as predictors of learner intentions. In the first model, when social issues were entered as a predictor, it was significant at (F $(1,131)=55.311, \mathrm{p}<0.001, \mathrm{R}^{2}=0.297$ and explained $29.7 \%$ of the challenges to learn online. The addition of lecturer issues in model 2 explained another $13.1 \%$ of the variance making a total variance of $42.8 \%$ (F $(2,130)=29.639, \mathrm{p}$ $=0.000, \mathrm{R}^{2}=0.131$. The addition of accessibility issues, academic issues, and generic issues in the subsequent stages could not make any impact on students' intention to study online with $\mathrm{p}>0.005$. In the final stage of the regression analysis, only lecturer issues were significant $(\beta=.36 \mathrm{p}=0.000)$ (Table 4). 
Table 4. Regression analysis of factors that are more likely to challenge students' intention to study online

\begin{tabular}{cccccc}
\hline Predictor & Regression & Regression & Regression & Regression & Regression \\
\hline Variables & 1 & 2 & 3 & 4 & 5 \\
Social Issues & $0.54^{* * *}$ & $0.29 * * *$ & 0.23 & 0.18 & 0.16 \\
Lecturer Issues & & $0.43^{* * *}$ & $0.40^{* * *}$ & $0.37^{* * *}$ & $0.36^{* * *}$ \\
Accessibility issues & & 0.19 & 0.15 & 0.14 \\
Academic Issues & & & 0.16 & 0.12 \\
Generic Issues & & & & 0.01 \\
R & 0.30 & 0.43 & 0.45 & 0.47 & 0.48 \\
$\mathrm{R}^{2}$ Change & & 0.13 & 0.03 & 0.02 & 0.01
\end{tabular}

Note $* * *=\mathrm{P}<0.001$

\section{Discussion}

The present study explores the challenges students in tertiary institutions have reported facing in online learning in the era of coronavirus pandemic. The study revealed that accessibility is the most important challenge students are facing in a complete online learning situation although all the other challenges reported higher means. Again, the study further revealed that students were not prepared for a complete online experience while social issues and lecturer issues affect students' intentions to study online.

Accessibility issues which include internet connectivity, using compatible smartphones and laptops have been identified by previous researchers. For instance, Muilenberg and Berge (2005) identified cost and access to the internet as less important barriers to online learning. However, the present study identified accessibility as an important challenge to online learning as this can be attributed to different geographical locations used for the studies. Whereas Muilenberg and Berge's (2005) study was conducted in a developed country, the present study took place in a developing country where internet connectivity is not strong, and some of the students do not have access to portable devices that can navigate the internet. Ahmed and Nwagwu (2006) supported the findings when they asserted that telecommunications, human resource development, ICT policies among others were the key challenges facing online learning in developing countries.

Findings from the current study revealed that students were not ready for an online learning experience in this pandemic era. Either students are afraid that they will encounter a lot of challenges by studying online or, they think the pandemic era is a period for family deliberations on how to get basic necessities and not for academics. Another important factor could be attributed to the fact that the students are already attached to the conventional approach. Pieces of literature have it that the introduction of new trends or improving an existing one is likely to meet resistance as people are sometimes attached to accepted pedagogies and propositions (9). Students' unwillingness to adopt the new approach can result in a failure to implement the whole process. Steinmayr and Spinath (2009) identified that motivational concepts contribute to students learning than general intelligence. Therefore, if students are not readily prepared to study online, intrinsically, they are not motivated and unwilling to learn. This supports the argument that the introduction of electronic learning initiatives has failed because institutions and their constituents were not prepared for the experience (Aydın \& Tasci, 2005; Borotis \& Poulymenakou, 2004).

The conventional classroom teaching where students and lecturers interact face-to-face is very key to promote socialisation. Social issues such as participating in group works, assisting each other to perform assignments, and looking at the facial gestures of lecturers when explaining a point are instrumental to facilitate learning in the conventional classroom. These things are minimal when students engage in an online learning situation. Although most of today's forms of e-learning approaches are towards communication, collaboration, and interactivity using face-toface and e-learning, the participants have never used the blended approach which was done primarily to improve the distribution of learning content. This is likely to make it difficult to assess even the course materials at the initial stage.

The use of the blended approach before students starts online learning should have assisted with issues such 
as lecturers encountering difficulties in teaching online and students' finding it difficult to assess course materials. Despite the emergency, remote teaching being the best available option for the COVID-19 pandemic, the high numbers displayed for means in the challenges studied indicates that students are less likely to benefit from this type of approach initiated by the institutions. The blended approach could have enabled the students and the lecturers to be transitioned smoothly to a purely online approach at this pandemic era. Hoic-Bozic, Mornar, and Boticki (2008) maintained that blended learning is the most effective way to transition from the traditional classroom to e-learning. This could have been important to assist lecturers to acquire the basic ideas that are relevant in online learning experiences.

\section{Recommendations}

To assist address accessibility issues, internet operators should ensure that internet connectivity is strong and also reduce the cost of internet bundles. The government should assist students to get laptops and tablets as some students rated challenges with phones and laptops as an important item. Another pragmatic approach would have been introducing students to online learning before the pandemic era. This could have given the students some online learning experience. Ideally, the ministry of education should encourage tertiary institutions in Ghana to use the blended approach where most of the interactions should be done using a conventional approach but conducting assessment and assessing course materials should be done online.

\section{Conclusion}

In conclusion, although engaging students in this pandemic era can be good to keep them active and busy with studies, there are a lot of challenges that should have been addressed before the pandemic era. For instance, the blended approach should have ushered students' to online learning before the change to complete online learning. To many of the students, online learning is something new and once they are in the pandemic era, they would have preferred the semester to be put on hold until further notice. Before adopting e-learning an organisation should consider the business environment, technology, content, training procedure, culture, human resources, and financial considerations (Borotis \& Poulymenakou, 2004). All these issues were not considered before the implementation of e-learning in tertiary institutions in Ghana. So, will the e-learning be effective in this pandemic era? Future studies should examine student's satisfaction in studying online from the convectional approach after the COVID-19.

\section{References}

Ahmed A, \& Nwagwu WE. (2006). Challenges and opportunities of e-learning networks in Africa. Development, 49(2), 86-92.

Ali A, \& Ahmad I. (2011). Key Factors for determining student satisfaction in distance learning courses: A study of Allama Iqbal open university. Contemporary Educational Technology, 2(2), 118-134.

Aung TN, \& Khaing SS. (2015). Challenges of implementing e-learning in developing countries: A review. International Conference on Genetic and Evolutionary Computing, 405-411.

Aydın CH, \& Tasci D. (2005). Measuring readiness for e-learning: Reflections from an emerging country. Journal of Educational Technology \& Society, 8(4), 244-257.

Borotis S, \& Poulymenakou A. (2004). E-learning readiness components: Key issues to consider before adopting e-learning interventions. In: Association for the Advancement of Computing in Education (AACE). In E-Learn: World Conference on E-Learning in Corporate, Government, Healthcare, and Higher Education (pp.1622-1629).

Buchanan DA. (2012). Case studies in organizational research. Qualitative organizational research, 5, 351-370.

Carr S. (2000). As distance education comes of age, the challenge is keeping the students. Chronicle of higher education, 46(23), 39-41.

Dudovskiy, J. (2018). Research methodology: Purposive sampling. Retrieved from The Ultimate Guide to Writing a Dissertation, In Business Studies-A step-by-step assistance: 2018. http://www.research-methodology.net.

Green SB, Lissitz RW, \& Mulaik SA. (1977). Limitations of coefficient alpha as an index of test unidimensionality1. 
Educational and Psychological Measurement, 37(4), 827-838.

Guglielmino LM, \& Guglielmino PJ. (2003). Identifying learners who are ready for e-learning and supporting their success. Preparing learners for e-learning, 18-33.

Hoic Bozic N, Mornar V, \& Boticki I. (2008). A blended learning approach to course design and implementation. IEEE transactions on education, 52(1), 19-30.

Kenny JD. (2003). Student perception of the use of online learning technology in their courses.

Maltby JR, \& Whittle J. (2000). Learning programming online: Student perceptions and performance. In Proceedings of the ASCILITE 2000 Conference.

Martin F, \& Bolliger DU. (2018). Engagement matters: Student perceptions on the importance of engagement strategies in the online learning environment. Online Learning, 22(1), 205-222.

Muilenburg LY, \& Berge ZL. (2005). Student barriers to online learning: A factor analytic study. Distance education, 26(1), 29-48.

Steinmayr R, \& Spinath B. (2009). The importance of motivation as a predictor of school achievement. Learning and individual differences, 19(1), 80-90.

Vasantha Raju N, \& Harinarayana NS. (2016). Online survey tools: A case study of Google Forms. National Conference on Scientific, Computational \& Information Research Trends in Engineering, GSSS-IETW.

Vaske JJ. (2008). Survey research and analysis: Applications in parks, recreation and human dimensions. Venture Pub, 23, 635 .

Watkins R, Leigh D, \& Triner D. (2004). Assessing readiness for e-learning. Performance Improvement Quarterly, 17(4), 66-79.

Worldometer. (2020). Coronavirus death toll. https://www.worldometers.info/coronavirus/coronavirus-death-toll/?fbclid $=$ IWAR3y7JhX2P7Si1x8hwwaSBJHVepxa0apOnfDc72-If7WZFEQTK6vrw1f570.

World Health Organisation. (2020). Coronavirus. https://www.who.int/health-topics/coronavirus\#tab=tab-1.

Zaheer M, Babar ME, Gondal UH, \& Qadri MM. (2015). E-learning and student satisfaction. In Proceedings of the 29th Annual Conference of the Asian Association of Open Universities: New frontiers in ODL (pp.275-285).

Zhou P, Yang XL, Wang XG, Hu B, Zhang L, Zhang W, Si HR, Zhu Y, Li B, Huang CL, \& Chen HD. (2020). A pneumonia outbreak associated with a new coronavirus of probable bat origin. Nature, 579(7798), 270-273.

Zhu N, Zhang D, Wang W, Li X, Yang B, Song J, Zhao X, Huang B, Shi W, Lu R, \& Niu P. (2020). A novel coronavirus from patients with pneumonia in China, 2019. New England Journal of Medicine, 82, 727-733. 